\title{
PEMBUATAN SISTEM ANTRIAN MENGGUNAKAN VISUAL BASIC 6.0 BERBASIS SENSOR INFRA MERAH
}

\author{
Indrianto \\ Jurusan Teknik Informatika \\ Sekolah Tinggi Teknik - PLN \\ email:Indrianto_basayev@yahoo.com,indrianto@sttpln.ac.id
}

\begin{abstract}
Dalam kehidupan sehari-hari antrian merupakan suatu hal yang pasti terjadi. Oleh karena itulah dibuat suatu sistem yang menangani antrian sehingga para pelanggan atau nasabah mendapat pelayanan yang baik.Tujuan tugas akhir ini adalah merancang dan mengimplementasikan suatu sistem antrian dengan menggunakan sensor infra merah, mikrokontroler, PC, monitor, dan speaker. Sensor infra merah digunakan sebagai pendeteksi adanya orang yang melintas. Switch digunakan sebagai penanda bahwa nomor antrian selanjutnya akan dilayani. Sensor dan switch tersebut terhubung dengan mikrokontroler dan keluaran dari mikrokontroler dihubungkan ke PC.

Hasilnya memperlihatkan bahwa bila ada orang yang melintasi sensor maka PC akan memberi perintah untuk mencetak nomor antrian. Switch yang ditekan akan mengubah nomor yang akan dilayani dan ditampilkan pada monitor dan diperdengarkan melalui speaker. Untuk menjalankan sistem ini digunakan bahasa pemrograman assembly dan Visual Basic yang memberikan instruksi kepda PC untuk mencetak nomor antrian dan memperdengarkan suara nomor antrian yang dilayani.
\end{abstract}

Kata Kunci:Microcontroller, AT89S52, Antiran, Infrared Sensor

\section{Latar Belakang}

Bagi perusahaan besar seperti bank, perusahaan asuransi, ataupun perusahaan yang memiliki pelayanan masyarakat, pelanggan atau nasabah merupakan investasi yang sangat besar. Mereka berusaha untuk memberikan pelayanan yang baik bagi para pelanggan atau nasabahnya. Salah satunya adalah pelayanan antrian otomatis yang memberikan kemudahan dan kenyamanan.

Dengan adanya sistem antrian ini pelanggan ataupun nasabah tidak perlu lagi berdiri berjajar menunggu giliran pelayanan. Saat ini sistem yang digunakan yaitu pelanggan yang masuk tinggal mengambil nomor antrian. Kemudian duduk menunggu giliran pelayanan sesuai dengan nomor antriannya, karena pada sistem antrian yang dibuat ini dipasang sensor pada pintu masuk ruangan khusus bagi pelanggan atau nasabah yang akan melakukan transaksi. Bila ada pelanggan atau nasabah yang masuk maka sensor akan mendeteksi dan nomor antrian akan dicetak secara otomatis. Pelanggan atau nasabah tinggal menunggu hingga nomor antriannya dipanggil untuk dilayani oleh customer service.

\section{LANDASAN TEORI}

\section{Teori Dasar Sistem}

Sistem adalah sekumpulan unsur/elemen yang saling berkaitan dan saling mempengaruhi dalam melakukan kegiatan bersama untuk mencapai suatu tujuan. Misalnya: sistem Komputer yang terdiri dari Software, Hardware, Brainware.

Secara umum model sistem sederhana digambarkan sebagai berikut:

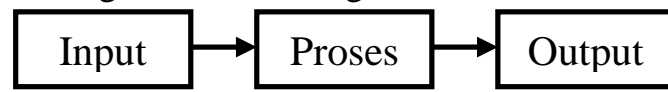

Menurut Ludwig Von Bartalanfy, Sistem merupakan seperangkat unsur yang saling terikat dalam suatu antar relasi 
diantara unsur-unsur tersebut dengan lingkungan.

Menurut Anatol Raporot, sistem adalah suatu kumpulan kesatuan dan perangkat hubungan satu sama lain.

Menurut L. Ackof, sistem adalah setiap kesatuan secara konseptual atau fisik yang terdiri dari bagian-bagian dalam keadaan saling tergantung satu sama lainnya.

\section{Karakteristik Sistem}

Sistem merupakan jaringan kerja dari beberapa prosedur yang saling berhubungan, berkumpul bersama untuk melakukan suatu kegiatan atau untuk menyelesaikan suatu sasaran yang tertentu. Sistem itu sendiri memiliki karakteristik atau beberapa sifat tertentu, yaitu mempunyai komponen (components), batas system (boundary), lingkungan luar sistem (environments), penghubung (interface), masukan (input), keluaran (output), pengolah (proses), dan sasaran tujuan (goal). [Jogiyanto, 1995;775]

Berikut ini karakteristik sistem yang dapat membedakan suatu sistem dengan sistem lainnya.

1. Batasan (boundary)

2. Lingkungan (environment)

3. Masukan (input)

4. Keluaran (output)

5. Komponen (component)

6. Penghubung(interface)

7. Penyimpanan(storage)

8. Sasaran sistem (objectives)

\section{Teori Antrian}

Antrian dapat terjadi apabila orang, komponen mesin atau unit barang harus menunggu untuk mendapatkan pelayanan dari fasilitas pelayanan yang sedang beroperasi pada kapasitas tertentu sehingga tidak melayani mereka untuk sementara waktu.

Ketika pelanggan menunggu untuk mendapatkan jasa pelayanan, maka keberadaan sistem antrian sangat diperlukan. Beberapa contoh berikut menunjukkan bahwa penggunaan sistem antrian sangat membantu untuk melancarkan pelayanan kepada pelanggan atau konsumen, seperti:

1. Pelanggan menunggu pelayanan di depan kasir
2. Mahasiswa menunggu untuk registrasi

3. Antrian untuk mengisi bahan bakar

4. Beberapa peralatan menunggu untuk diservis/diperbaiki

5. Pesawat terbang menunggu pelayanan menara pengawas untuk melakukan landing atau take-off

Pengertian antrian menurut Ma'arif dan Tanjung (2003: 119) adalah sebagai berikut:

"Situasi barisan tunggu dimana sejumlah kesatuan fisik (pendatang) sedang berusaha untuk menerima pelayanan dari fasilitas terbatas (pemberi pelayanan), sehingga pendatang harus menunggu beberapa waktu dalam barisan agar dilayani”.

Sedangkan menurut Heizer dan Render (2006: 658) dalam bukunya Operation Management yang diterjemahkan oleh Setyoningsih dan Almahdy adalah sebagai berikut:

"Teori antrian adalah ilmu pengetahuan tentang antrian dan antrian merupakan orang-orang atau barang dalam barisan yang sedang menunggu untuk dilayani”.

Berdasarkan definisi di atas maka dapat disimpulkan bahwa antrian adalah suatu proses yang berhubungan dengan suatu kedatangan seseorang pelanggan pada suatu fasilitas pelayanan, kemudian menunggu dalam suatu antrian dan pada akhirnya meninggalkan fasilitas tersebut. Jadi sistem antrian adalah himpunan pelanggan, pelayan dan suatu aturan yang mengatur kedatangan para pelanggan dan pemroses masalahnya.

\section{Komponen Sistem Antrian}

Komponen suatu sistem antrian terdiri dari sumber populasi, kedatangan antrian atau garis tunggu dan pelayanan atau server seperti yang digambarkan dalam gambar sebagai berikut:

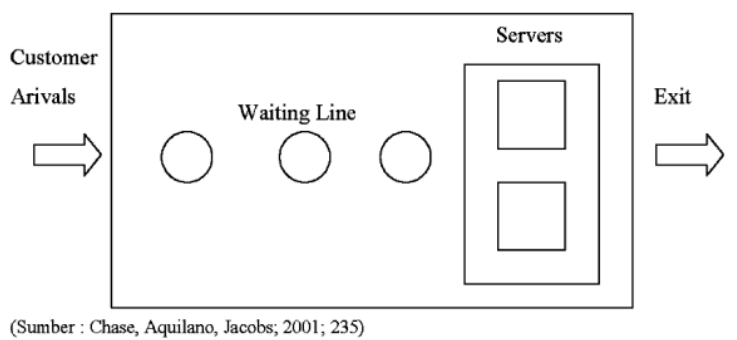




\section{Elemen-elemen Dasar Teori Antrian}

a. Sumber Masukan (Input)

Sumber masukan dari suatu sistem antrian dapat terdiri atas suatu populasi orang,barang, komponen atau kertas kerja yang datang pada sistem untuk dilayani.

b. Pola kedatangan

Cara dengan mana individuindividu dari populasi memasuki sistem disebut pola kedatangan (arrival pattern). Individu-individu mungkin datang dengan tingkat kedatangan (arrival rate) yang konstan ataupun acak/random (yaitu berapa banyak individu-individu per periode waktu). Tingkat kedatangan produkproduk yang bergerak sepanjang lini perakitan produksi massa mungkin konstan, sedang tingkat kedatangan telephone calls sangat sering mengikuti suatu distribusi probabilitas Poisson.

Variasi yang mungkin lainnya dalam pola kedatangan adalah kedatangan dari kelompok-kelompok individu. Bila lebih dari satu individu memasuki suatu sistem seketika secara bersama, maka terjadi dengan apa yang disebut bulk arrivals.

c. Disiplin Antrian

Displin antrian menunjukkan pedoman keputusan yang digunakan untuk menyeleksi individu-individu yang memasuki antrian untuk dilayani terlebih dahulu (prioritas). Disiplin antrian yang paling umum adalah pedoman first come, first served (FCFS), yang pertama kali datang pertama kali dilayani. Tetapi bagaimanapun juga ada beberapa tipe disiplin antrian lainnya yang dapat termasuk dalam modelmatematis antrian. Model-model yang disajikan disini dibatasi untuk disiplinantrian FCFS.

$\begin{array}{lr}\text { Beberapa } & \text { disiplin antrian } \\ \text { lainnya ialah } & \text { pedoman-pedoman } \\ \text { shortest-operating } & \text { (service)-time }\end{array}$ (SOT), last come-first served (LCFS), longest-operating-time (LOT), dan service in random order (SIRO). Dalam rumah sakit-rumah sakit dan fasilitas-fasilitas kesehatan lainnya mungkin mempunyai pedomanpedoman yang berbeda, seperti "emergency first" atau "critical condition first".

d. Kepanjangan Antrian

Banyak sistem antrian dapat menampung jumlah individu-individu yang relative besar, tetapi ada beberapa sistem yang mempunyai kapasitas yang terbatas. Bila kapasitas antrian menjadi faktor pembatas besarnya jumlah individu yang dapat dilayani dalam sistem secara nyata, berarti sistem mempunyai kepanjangan antrian yang terbatas (finite); dan model antrian terbatas harus digunakan untuk menganalisa sistem tersebut.

e. TingkatPelayanan

Waktu yang digunakan untuk melayani individu-individu dalam suatu sistem disebut waktu pelayanan (service time). Waktu ini mungkin konstan, tetapi juga sering acak (random). Bila waktu pelayanan mengikuti distribusi eksponensial atau distribusinya acak, waktu pelayanan (yaitu unit/jam) akan mengikuti suatu distribusi Poisson.

f. $\operatorname{Keluar}($ Exit)

Sesudah seseorang (individu) telah selesai dilayani, dia keluar (exit) dari sistem. Sesudah keluar, dia mungkin bergabung pada satu di antara kategori populasi. Dia mungkin bergabung dengan populasi asal dan mempunyai probabilitas yangf sama untuk memasuki sistem kembali, atau dia mungkin bergabung dengan populasi lain yang mempunyai probalitas lebih kecil dalam hal kebutuhan pelayanan tersebut kembali.

\section{Teknologi Komputer}

Komputer adalah suatu alat elektronik yang mampu melakukan beberapa tugas sebagai berikut:

1. menerima tugas,

2. memproses input tadi sesuai dengan programnya,

3. menyimpan perintah-perintah dan hasil dari pengolahannya,

4. menyediakan output dalam bentuk informasi.

Komputer adalah sistem elektronik untuk memanipulasi data yang cepat dan 
tepat serta dirancang dan diorganisasikan supaya secara otomatis menerima dan menyimpan data input, memprosesnya, dan menghasilkan output di bawah pengawasan suatu langkah-langkah instruksi-instruksi program yang tersimpan di memori (stored program).

Komputer adalah alat elektronik yang berfungsi menerima dan mengolah data dengan menggunakan suatu program yang tersimpan di dalam komputer. Kemudian dari data tersebut menghasilkan informasi yang berguna bagi pengguna (Hartono, 2004: 2).

\section{Sensor}

Sensor merupakan bagian dari transducer yang berfungsi untuk melakukan sensing atau "merasakan dan menangkap" adanya perubahan energi eksternal yang akan masuk ke bagian input dari transducer, sehingga perubahan kapasitas energi yang ditangkap segera dikirim kepada bagian konvertor dari transducer untuk dirubah menjadi energi listrik. Berikut adalah macam - macam sensor :

1. Sensor cahaya adalah alat yang digunakan untuk merubah besaran cahaya menjadi besaran listrik. Prinsip kerja dari alat ini adalah mengubah energi foton menjadi elektron. Salah satu penggunaannya yang paling populer adalah kamera digital.

2. Sensor Sinar terdiri dari 3 (tiga) kategori, antara lain :

a. Fotovoltaic atau sel solar adalah alat sensor sinar yang mengubah energi sinar langsung menjadi energi listrik, dengan adanya penyinaran cahaya akan menyebabkan pergerakan elektron dan menghasilkan tegangan.

b. Fotokonduktif (fotoresistif) yang akan memberikan perubahan tahanan (resistansi) pada selselnya, semakin tinggi intensitas cahaya yang terima, maka akan semakin kecil pula nilai tahanannya.

c. Fotolistrik adalah sensor yang berprinsip kerja berdasarkan pantulan karena perubahan posisi/jarak suatu sumber sinar (inframerah atau laser) ataupun target pemantulnya, yang terdiri dari pasangan sumber cahaya dan penerima.

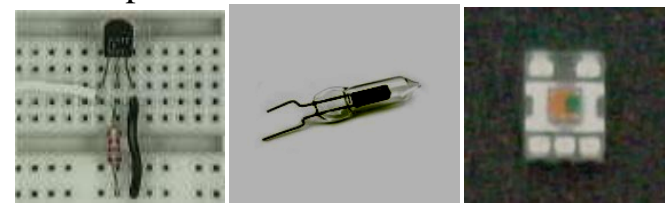

8. Mikrokontroler

Mikrokontroler adalah sebuah chip yang berfungsi sebagai pengontrol rangkaian elektronik dan umumnya dapat menyimpan program di dalamnya (Budiharto, 2004: 133).

Mikrokontroler merupakan sistem komputer yang di dalamnya terdiri atas CPU, memori, clock, bus (jalur), serta sarana I/O yang mempunyai satu atau beberapa tugas yang sangat spesifik. Perbedaan yang lainnya adalah perbandingan RAM dengan ROM yang sangat berbeda antara komputer dengan mikrokontroler. Dalam mikrokontroler kapasitas ROM jauh lebih besar dibandingkan RAM, sedangkan dalam komputer atau PC, RAM jauh lebih besar dibandingkan ROM.

Sebuah mikrokontroler dapat bekerja jika dalam mikrokontroler tersebut terdapat sebuah program yang berisi instruksi-instruksi yang dapat digunakan untuk menjalankan sistem mikrokontroler tersebut. Instruksi-instruksi dari sebuah program pada setiap jenis mikrokontroler mempunyai jenis mikrokontroler yang digunakan.

\section{Program dan Bahasa Pemrograman}

Program adalah sekumpulan instruksi yang dijalankan oleh komputer. Program-program ini dibuat dengan suatu bahasa pemrograman, yaitu suatu bahasa yang digunakan oleh pemrogram untuk memberi perintah atas instruksi kepada komputer.

Terdapat beberapa level bahasa pemrograman, yaitu :

1. Bahasa pemrograman tingkat rendah

Bahasa ini lebih dekat dengan perangkat keras, sehingga tampak primitif dan sulit dimengerti oleh programmer awam. Contohnya adalah bahasa Assembly

2. Bahasa pemrograman tingkat tinggi 
Bahasa ini lebih dekat dengan bahasa manusia, dalam hal ini bahasa Inggris, sehingga jauh lebih mudah dipahami. Contoh : Pascal dan C

3. Bahasa pemrograman berorientasi objek

Bahasa pemrograman ini mengandung fungsi-fungsi untuk menyelesaikan suatu permasalahan. Programmer tidak harus menulis secara detail semua pernyataan, tetapi cukup memasukkan kriteria-kriteria yang dikehendaki saja. Contoh : Visual Basic, Delphi.

4. Bahasa pemrograman generasi ke empat (SQL)

Bahasa ini mirip dengan kalimat bahasa Inggris dan lebih familiar dibandingkan bahasa tingkat tinggi, dimana kita memasukkan sejumlah kata untuk menyatakan suatu proses atau mendapatkan suatu hasil. Namun semua perintah tersebut haruslah diketik. Contoh MySQL.

\section{Bahasa Pemrograman Visual Basic 6.0}

Bahasa pemrograman Visual Basic merupakan salah satu pemrograman tingkat tinggi. Microsoft Visual Basic merupakan salah satu bahasa pemrograman yang digunakan untuk membuat aplikasi windows yang berbasis grafis (GUI Graphical User Interface) atau program yang memungkinkan pemakai komputer berkomunikasi dengan komputer tersebut dengan modus grafik atau gambar.

Visual Basic berawal dari bahasa pemrograman Basic (Beginners All Purpose Symbolic Intructin Code). Tahun 1980-an sistem operasi DOS cukup popular di kalangan pemakai PC karena di dalamnya disertakan bahasa Basic yang dikenal dengan QBASIC (Quick Basic). Visual Basic pertama kali diperkenalkan pada tahun 1991 yaitu program Visual Basic untuk DOS dan Windows. Di era Windows, Microsoft menciptakan Visual Basic yang terus mengalami penyempurnaan hingga Visual Basic 6.0.

Versi awal diciptakan oleh Alan Cooper dan kemudian menjualnya ke Microsoft yang mengambil alih pengembangan produk dengan memberi nama sandi "Thunder". Akhimya Visual Basic menjadi bahasa pemrograman utama di lingkungan Windows. Sebelum mencapai kepopuleran seperti sekarang. Visual Basic telah dirilis beberapa kali seperti berikut :

a. Versi 1.0 dirilis bulan Mei 1991.

b. Januari 1992 dilengkapi control custom (Professional Toolkit).

c. Versi 2.0 yang lebih "canggih" dirilis pada bulan Oktober 1992.

d. Versi 3.0 dirilis tahun 1993 dengan "Development Tool" andal.

e. Versi 4.0 dirilis tahun 1995 dilengkapi Object Oriented Programming, mulai dipakai untuk mengembangkan aplikasi berbasis Windows.

f. Versi 5.0 dirilis tahun 1997 dengan Integrated Development Environment (IDE).

g. Versi 6.0 dirilis tahun 1998 bersama dengan Microsoft Visual Studio.

h. Versi .NET dirilis tahun 2001, yaitu Visual Basic.NET bersama dengan Microsoft Visual Studio.NET.

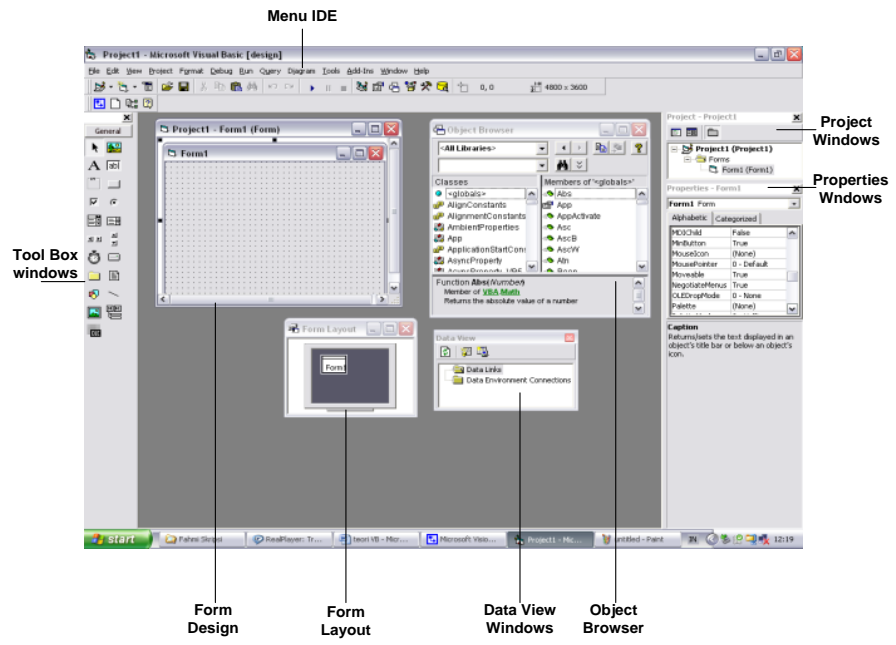

Tampilan IDE Microsoft Visual Basic 6.0

\section{Bahasa Assembly}

Secara umum bahasa pemrograman mikrokontroler adalah bahasa tingkat rendah yaitu bahasa assembler, dimana setiap mkriokontroler memiliki bahasa pemrograman yang berbeda-beda. Karena banyaknya hambatan dalam penggunaan bahasa assembler, maka mulai dikembangkan compiler atau penerjemah untuk bahasa tingkat tinggi.

Dalam perancangan sistem antrian penulis menggunakan bahasa pemrograman Assembly dengan menggunakan software Pinnacle 52.

\section{Mengenal Bahasa Assembly}


Secara fisik, mirokontroler bekerja dengan membaca instruksi yang tersimpan di dalam memori. Mikrokontroler menentukan alamat dari memori program yang akan dibaca, dan melakukan proses baca data di memori. Data yang dibaca dinterpretasikan sebagai instruksi. Alamat instruksi disimpan oleh mikrokontroler di register, yang dikenal sebagai program counter. Instruksi ini misalnya program aritmatika yang melibatkan 2 register.

AT89S52 memiliki sekumpulan instruksi yang sangat lengkap. Jika anda telah mempelajari bahasa assembly mikroprosesor keluarga Intel (misal 8086), ada sedikit perbedaan dengan bahasa assembly di mikrokontroler. Intstruksi MOV untuk byte dan bit dikelompokkan sesuai dengan mode pengalamatan (addressing modes). Mode pengalamatan menjelaskan bagaimana operand dioperasikan. Berikut penjelasan dari berbagai mode pengalamtan. Bentuk program assembly yang umum ialah:

Isi memori ialah bilangan heksadesimal yang dikenal oleh mirokontroler kita, yang merupakan representasi dari bahasa assembly yang telah kita buat. Mnemonic atau opcode ialah kode yang akan melakukan aksi terhadap operand. Operand ialah data yang diproses oleh opcode. Sebuah opcode bisa membutuhkan 1, 2 atau lebih operand, kadang juga tidak perlu operand. Sedangkan komentar dapat kita berikan dengan menggunakan tanda titik koma (;). Berikut contoh jumlah operand yang berbeda-beda dalam suatu assembly.

\section{Bahasa Mikrokontroler}

Secara umumm bahasa pemrograman mikrokontroler adalah bahasa tingkat rendah yaitu bahasa assembler, dimana setiap mikrokontroler memiliki bahasa pemrograman yang berbeda-beda. Karena banyaknya hambatan dalam penggunaan bahasa assembler, maka mulai dikembangkan kompiler atau penerjemah untuk bahasa tingkat tinggi.

Dalam perancangan sistem antrian penulis menggunakan bahasa pemrograman Assembly dengan menggunakan software Pinnacle 52.

\section{Pinnacler $52 \quad$ Professional Development System \\ Pinaccle 52 merupakan software} compiler dengan menggunakan bahasa assembly yang dibuat untuk melakukan pemrograman chip-chip mikrokontroller tertentu, salah satunya AT89S52. Interface dari Pinnacle dapat dilihat pada gambar dibawah ini.

\section{ISP-Flash Programmer 3.0a}

Software ini digunakan untuk menuliskan program ke dalam mirokontroler AT89Sxx. Software ini merupakan software freeware yang dibuat dan dikembangkan oleh Muhammad Asim Khan dari Pakistan.

Dengan ISP Flash Programmer ini program yang telah dibuat dapat dituliskan ke dalam mikrokontroler.

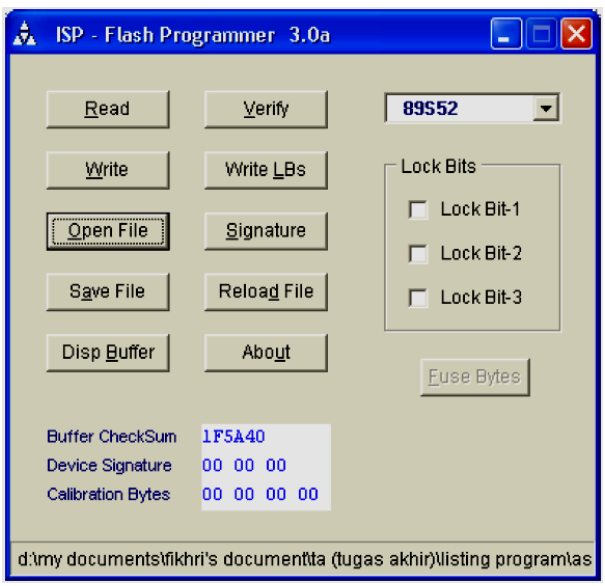

ISP-Flash Programmer $3.0 a$

III. ANALISA

DAN

\section{PERANCANGAN}

\section{Gambaran Umum}

Pada rancang bangun sistem antrian menggunakan sensor infra merah ini terdiri dari dua bagian yaitu perancangan (hardware) dan perancangan (software).

Pada tahap perancangan perangkat keras ada beberapa pengerjaan atau perancangan yang dilakukan yaitu perancangan rangkaian elektronik, perancangan konstruksi atau mekanik. Sedangkan pada tahap perancangan perangkat lunak yaitu perancangan program pada PC dan perancangan program pada mikrokontroler. 
Karena banyaknya pembahasan pada rancang bangun sistem antrian ini dan telah disebutkan pada Bab I mengenai pembatasan masalah maka pada Bab ini akan dijelaskan tentang perancangan sistem antrian berbasis sensor infra merah dengan bahasa pemrograman Visual Basic 6.0 yang dibatasi pada pembuatan program aplikasi dan pengecekan hasil yang didapatkan serta bagaimana aplikasi tersebut berjalan. Sistem operasi yang digunakan adalah Windows XP.

\section{Analisis Kebutuhan Sistem}

Membangun sebuah aplikasi yang bertujuan untuk mengendalikan suatu antrian memang suatu hal yang lumrah di zaman sekarang ini, tetapi dalam hal ini kontrolnya adalah sensor infra merah. Pemasarangan dan instalasi untuk alat kontrol ini lebih mudah dan dapat memberikan banyak efisiensi. Sistem yang dirancang ini dapat diaplikasikan pada suatu ruangan.

Adapun spesifikasi perangkat keras yang dibutuhkan adalah:

a. Komputer Laptop:

- Pentium IV

- RAM 512

- Harddisk 40 GB

- VGA $64 \mathrm{MB}$

- CD/DVD ROM

- Mouse

- Audio port

- USB port

b. Monitor 17 "

c. Speaker stereo dan amplifier

d. Rangkaian sensor infra merah dan switch 3 buah

e. Kabel konverter USB to RS232

Adapun perangkat lunak yang dibutuhkan adalah:

a. Sistem operasi Windows XP SP2

b. Microsoft Visual Basic 6.0

c. Pinnacle 52 Professional Development System

d. ISP-Flash Programmer 3.0a

e. USB driver

Pada tahap analisis sistem ini, semua kebutuhan perangkat lunak didefinisikan sesuai dengan tujuan yang ingin dicapai. Adapun analisis tersebut menyangkut tentang masukan (input) dan keluaran (output) dari perangkat lunak untuk menjadikan masukan yang ada menjadi keluaran yang diharapkan.

Perangkat lunak yang akan dibangun adalah aplikasi sistem antrian berbasis sensor infra merah dimana proses pemberian input ke mikrokontroler dari sensor inframerah kemudian mikrokontroler akan memberikan input kepada PC untuk mencetak nomor antrian menggunakan printer. Input dari switch yang diberikan pada mikrokontroler AT89S52 merupakan tanda bahwa nomor selanjutnya akan dilayani dan akan diteruskan sebagai input ke komputer sehingga nomor yang dipanggil ditampilkan pada monitor dan pada PC akan diperdengarkan suara nomor antrian melalui speaker.

\section{Interfacing IIC Bus Pada Serial Port.}

Untuk komunikasi data dari alat ke komputer disini digunakan konektor yang menghubungkan komputer dengan mengambil level tegangan RS232 yang ada pada komputer yang dihubungkan secara serial.

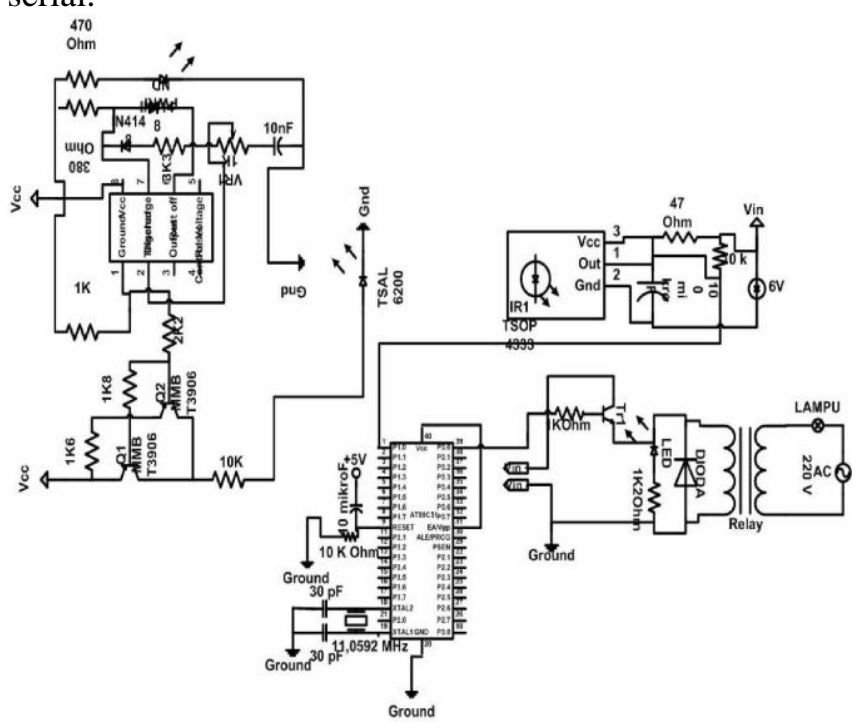

\section{Rangkaian Sensor Infra Merah}

Prinsip dasar dari transfer data dengan mengunakan IIC Bus secara serial. Pin yang dipakai disini ada 3 pin yang terhubung pada pin RS232 di komputer, yaitu:

- Port 3.0: TxD (transmit Data)

Berfungsi untuk memberitahu DCE atau disini adalah sensor infra merah bahwa DTE telah aktif dan siap untuk bekerja. 
- Port 3.1: RxD

Mengindikasikan kesiapan dari DTE. Sinyal ini ON oleh DTE saat siap untuk mengirim atau menerima data.

\section{- Pin 20: Ground}

Berguna untuk menetralisir arus listrik statis.

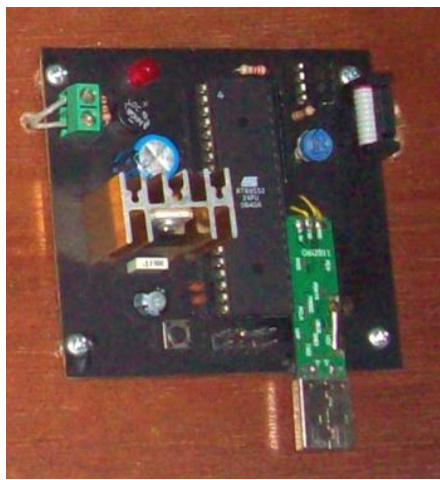

Tata letak rangkaian sensor infra merah

\section{Perancangan Sistem}

Pada dasarnya perancangan sistem yang dibuat oleh penulis adalah mengenai proses pemberian input ke mikrokontroler dari sensor inframerah kemudian mikrokontroler akan memberikan input kepada PC untuk mencetak nomor antrian menggunakan printer. Input dari switch yang diberikan pada mikrokontroler AT89S52 merupakan tanda bahwa nomor selanjutnya akan dilayani dan akan diteruskan sebagai input ke komputer sehingga nomor yang dipanggil ditampilkan pada monitor dan pada PC akan diperdengarkan suara nomor antrian melalui speaker.

Karena pembahasan pada Tugas Akhir ini hanya dibatasi pada bahasa pemrograman Visual Basic dan Assembly pada sistem antrian maka penulis hanya akan membahas secara khusus mengenai pemrograman dan pada pemrograman tersebut.

Berikut adalah blok diagram sistem antrian menggunakan sensor infra merah.

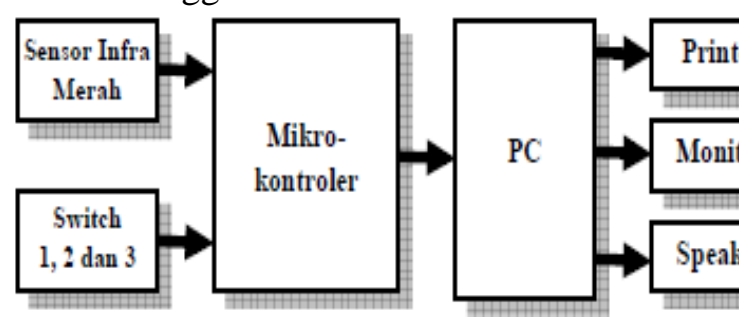

Blok Diagram sistem antrian menggunakan sensor infra merah
Pada gambar di atas memperlihatkan blok diagram dari alat yang dirancang.

- $\quad$ Mikrokontroler AT89S52
Merupakan komponen utama yang berfungsi sebagai pengolah data dan menerima input dari sensor infra merah dan switch kemudian memberikan output pada PC.

- $\quad$ Sensor inframerah

Merupakan komponen yang digunakan untuk mendeteksi adanya orang yang masuk ke dalam ruangan.

- $\quad$ Monitor

Merupakan komponen yang digunakan untuk menampilkan nomor antrian yang akan dilayani dan Loket mana yang akan melayani.

- $\quad$ Switch

Merupakan komponen yang berfungsi sebagai input yang akan diberikan pada PC sebagai penanda Loket yang akan melayani.

- $\quad$ PC (Personal Computer)

Merupakan unit yang berfungsi sebagai pengolah data, mengeluarkan sinyal audio pada speaker, memberikan perintah kepada printer untuk mencetak nomor antrian.

- $\quad$ Printer

Merupakan unit yang berfungsi untuk mencetak nomor antrian.

- $\quad$ Speaker

Merupakan unit yang akan berfungsi untuk mengeluarkan suara panggilannomor antrian yang akan dilayani dan Loket mana yang akan melayani.

\section{Perancangan Program}

Berdasarkan dari blok diagram dan cara kerja dari sistem antrian maka dibuatlah rancangan program. Dalam merancang program penulis terlebih dahulu akan membuat pemodelan fungsi atau proses dan Flowchart sebagai panduan untuk pembuatan program.

Dalam membuat program harus diperhatikan agar program tersebut 
mempunyai aturan logika yang benar, tentu akan menyebabkan adanya kesalahan dari hasil keluaran program tersebut, untuk itu sebelum membuat program terlebih dahulu program dirancang menggunakan flowchart. Pembuatan flowchart ini dimaksudkan untuk mempermudah dalam pembuatan program nantinya dan untuk membantu melacak kebenaran logika sebuah program dan membantu untuk memahami sebuah persoalan sebelum menuliskan kode-kode programnya.

Berikut ini adalah flowchart dari sistem antrian menggunakan sistem infra merah:

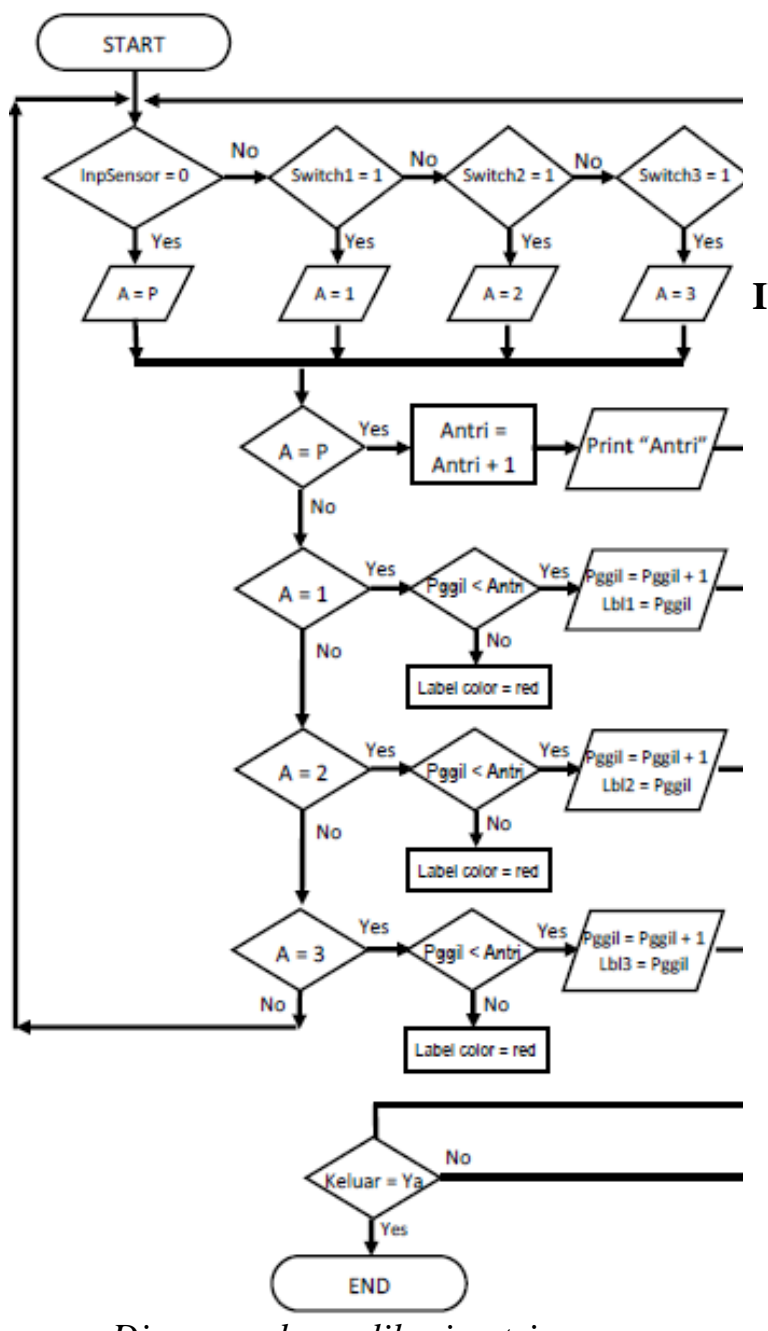

\section{Logika Program:}

Mulai

Cek sensor,

jika sensor $=0$, maka $\mathrm{A}=\mathrm{P}$

jika switch 1 ditekan maka $\mathrm{A}=1$

jika switch 2 ditekan maka $A=2$

jika switch 3 ditekan maka $\mathrm{A}=3$ jika tidak ulangi

Periksa nilai input

jika input $=\mathrm{P}$, maka tambah Antri dengan 1, cetak Antri

jika input $=1$, maka periksa

jika Pggil lebih kecil dari Antri maka tambah Pggil dengan 1 dan Lbl1 = Pggil

jika input $=2$, maka periksa jika Pggil lebih kecil dari Antri maka tambah Pggil dengan 1 dan Lbl2 $=$ Pggil

jika input $=3$, maka periksa

jika Pggil lebih kecil dari Antri maka tambah Pggil dengan 1 dan Lbl3 = Pggil

jika tidak, ulangi cek input

cek apakah Keluar $=$ Ya

jika Ya maka akhiri program

jika Tidak lanjutkan

Ulangi program

\section{IMPLEMENTASI}

DAN

\section{PENGUJIAN}

Setelah melakukan analisis kebutuhan dan perancangan perangkat lunak, langkah selanjutnya adalah pengkodean (Implementasi) dan pengujian, hal ini didasarkan pada model sekuensial linier yang digunakan pada penelitian ini.

Implementasi

merupakan penerapan desain (perancangan) sistem yang telah dilakukan sebelumnya kedalam bentuk yang dapat dimengerti oleh mesin dengan spesifikasi perangkat lunak serta perangkat keras yang digunakan.

Tahap pengujian difokuskan pada logika internal perangkat lunak, yang memastikan bahwa seluruh pernyataan telah diuji, dan fungsi ekternal, yaitu pengujian yang dilakukan untuk menemukan kesalahan-kesalahan dan memastikan bahwa masukan yang didefenisikan menghasilkan keluaran yang diinginkan.

Tahap pengujian ada 2 bagian yaitu berupa skenario pengujian dan pengujian (testing). Untuk lebih jelasnya dibuatkan sebuah tabel skenario pengujian, hal ini bertujuan untuk memberikan keterangan tentang apa saja yang akan diuji.

\section{Implementasi Proses}

Pengkodean diperlukan agar rancangan dapat diterjemahkan kedalam bentuk mesin dan dapat dijalankan. Pada 
bab ini penulis akan memberikan penggalan garis program untuk beberapa proses yaitu :

\section{DeteksiHardware}

Ketika aplikasi dijalankan yang pertama dilakukan adalah memeriksa apakah perangkat sensor sudah terhubung dengan PC. Jika belum maka aplikasi akan menampilkan pesan error. Agar alat dapat terhubung dengan baik pada PC, maka perlu dilakukan inisialisasi Port Serial, yaitu: Port $=$ Com11; Bit Start $=1$; Baud rate $=9600 ;$ Parity $=$ None; Bit Stop $=$ 1.Listring programnya adalah sebagai berikut:

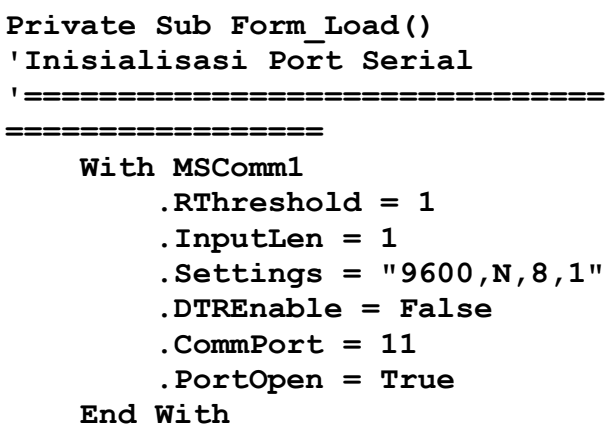

\section{Pengujian}

Setelah dilakukan implementasi, maka tahap selanjutnya yaitu tahap pengujian, Pada tahap ini akan diuraikan mengenai skenario pengujian analisis hasil pengujian.

\section{Skenario Pengujian}

Pengujian aplikasi sistem antrian yang dibangun diperlukan skenario pengujian, yaitu menggunakan metode black box dengan cara memberikan sejumlah masukan pada program yang akan diproses sesuai dengan kebutuhan fungsionalnya untuk menghasilkan keluaran yang diinginkan.

\section{Hasil Percobaan Menggunakan}

Program Pada Sensor Infra Merah

Sensor infra merah dihubungkan pada port 0.3 pada mikrokontroler. Pada sensor infra merah ini led infra merah berfungsi sebagai transmitter dan photodioda sebagai receiver. Led infra merah dan photodioda dipasang berhadapan, Jika sinar infra merah yang dipancarkan oleh led infra merah terputus maka keluaran dari sensor adalah 0 . Keluaran dari sensor ini diberikan pada mikrokontroler dan mikrokontroler akan memberikan keluaran 0 pada Port 3.1.
Keluaran dari Port 3.1 ini merupakan input ke PC sehingga bila sensor terhalangi maka pada PC akan tampil nomor antrian 1 yang dicetak, dan printer akan mencetak nomor antrian tersebut.

\section{Hasil Percobaan Menggunakan Program Pada Switch}

Disini terdapat tiga switch yang masing masing dihubungkan pada Port 0.0 sampai port 0.3. Jika switch 1 ditekan maka Port 0.0 pada mikrokontroler AT89S52 akan menerima input lalu accumulator akan diisi dengan karakter 1, kemudian karakter 1 tersebut akan dikirim ke komputer. Bila switch 2 ditekan, maka port 0.1 pada mikrokontroler AT89S52 akan menerima input lalu accumulator akan diisi dengan karakter 2, kemudian karakter 2 tersebut akan dikirimkan ke komputer. Bila switch 3 ditekan, maka port 0.2 pada mikrokontroler AT89S52 akan menerima input lalu accumulator akan diisi dengan karakter 3, kemudian karakter 3 tersebut akan dikirimkan ke komputer. Selanjutnya program membaca karakter tersebut lalu pada monitor akan menampilkan nomor antrian yang akan dilayani pada loket yang menekan switch dan terdengar suara panggilan nomor antrian pada loket yang menekan switch.

\section{Pengoperasian}

Aplikasi sistem antrian yang telah menjadi program executable file bisa dipanggil melalui Windows Explorer yang dapat disimpan dimana saja dalam direktori dan media penyimpanan apa pun dengan kapasitas yang kecil. Ketika aplikasi dijalankan maka yang pertama muncul adalah jendela Login.

\section{Login}

Ketika aplikasi dijalankan yang pertama tampil adalah jendela Login. Pada jendela ini user diminta untuk memasukkan Username dan Password lalu mengklik tombol OK untuk konfirmasi atau CANCEL untuk membatalkan. 


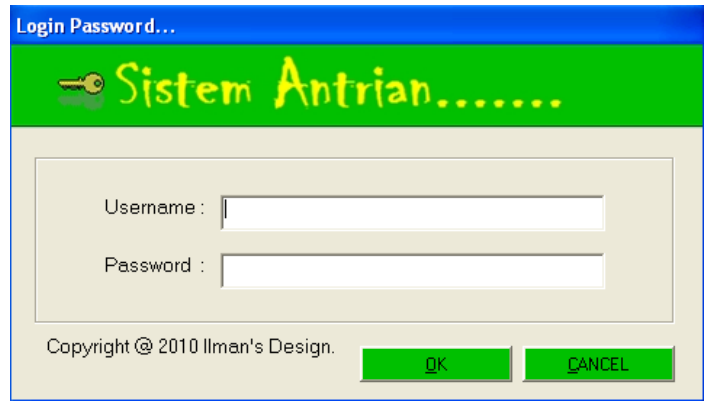

Jika user memilih dan klik tombol CANCEL, maka aplikasi akan menampilkan jendela konfirmasi apakah pilih YES jika user benar-benar akan keluar dari aplikasi atau NO untuk kembali ke jendela Login.

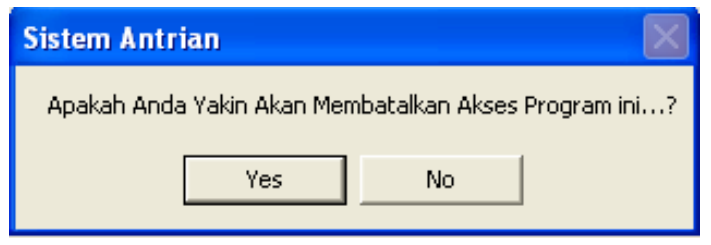

\section{Jendela Aplikasi Sistem Antrian}

Jika user telah memasukkan Username dan Password dengan benar dan mengklik tombol OK, beberapa saat akan tampil Splashscreen.

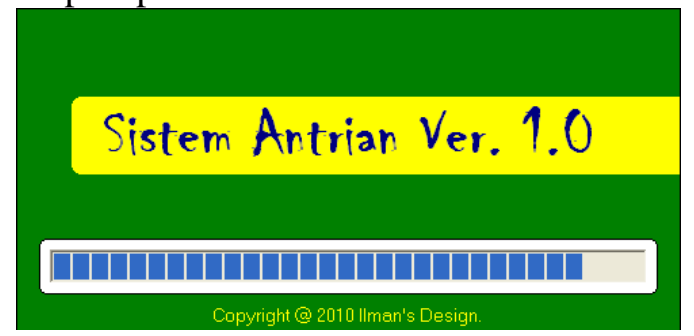

Selanjutnya di layar monitor menampilkan jendela utama Aplikasi Sistem Antrian.

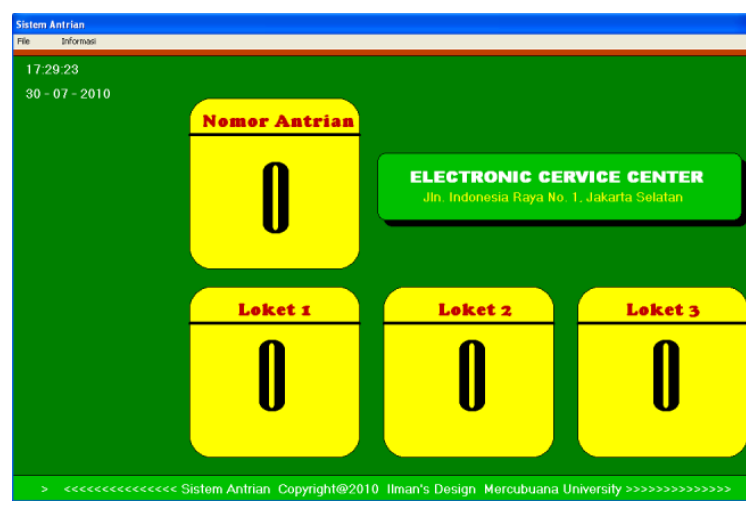

Pada Jendela Aplikasi Sistem Antrian terdapat Menu bar dan tampilan layar nomor antrian serta Loket.

\section{a. Menu File}

Menu File apabila diklik akan muncul beberapa pilihan, yaitu Setting, Ubah Password, dan Exit.

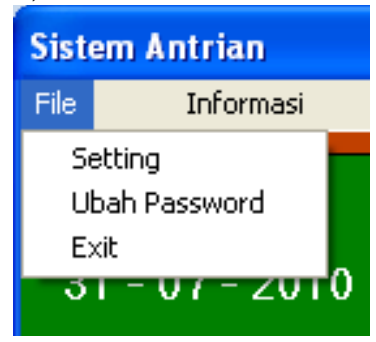

- $\quad$ Setting

Perintah ini untuk memberikan keterangan tambahan mengenai perusahaan yang menggunakan Aplikasi Sistem Antrian ini. Jika diklik maka akan tampil jendela Setting.

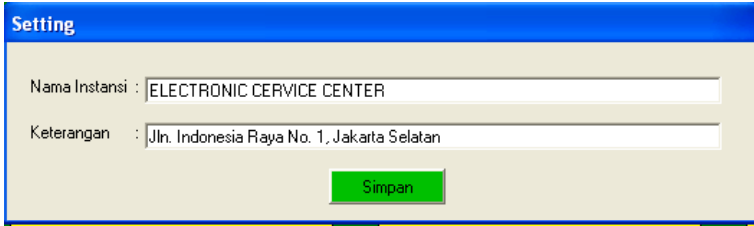

Setelah kotak Nama Instansi dan Keterangan diisi oleh User dan menekan tombol Simpan, maka Nama Instansi dan Keterangan akan tampil dilayar.

\section{ELECTRONIC GERMIGE GENTER} JIn. Indonesia Raya No. 1. Jakarta Selatan

\section{- Ubah Password}

Perintah ini untuk mengganti Username dan Password pada saat Login. Jika diklik maka akan tampil jendela Ganti Password dan user diminta untuk mengisi Username dan Password. 


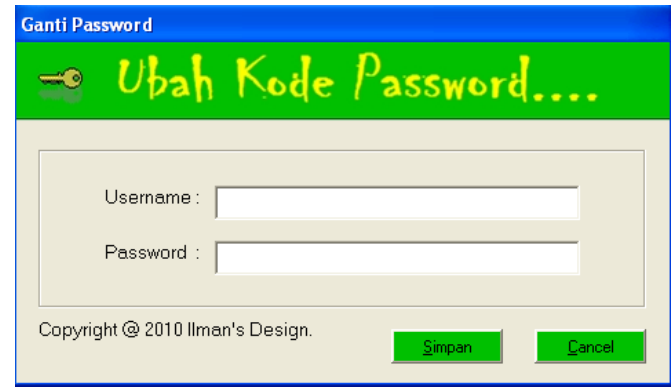

- Exit

Perintah ini untuk menutup Aplikasi. Bila diklik maka akan tampil jendela konfirmasi yang menanyakan apakah user akan keluar dari Aplikasi. Jika user memilih tombol Yes maka Aplikasi Sistem Antrian akan ditutup, jika memilih No maka akan kembali ke Jendela Aplikasi.

\section{Sistem Antrian}

Apakah Anda yakin akan keluar dari Program ini?

Yes No

\section{b. Menu Informasi}

Pada menu Informasi hanya terdapat pilihan About Program. Bilamana pilihan About Program diklik, maka akan tampil jendela informasi Aplikasi Sistem Antrian.

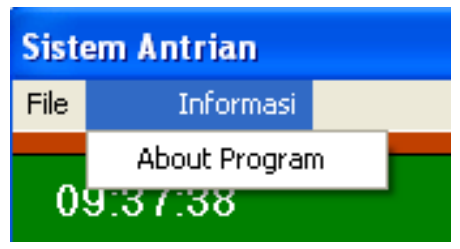

Menu Informasi

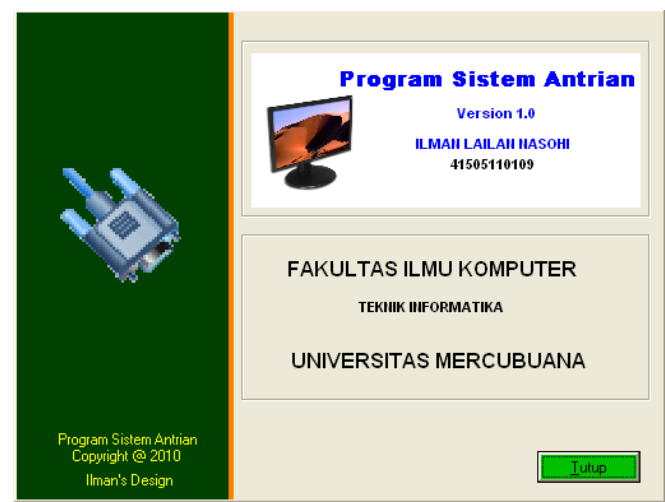

Informasi Aplikasi Sistem Antrian

\section{Pencetakan Nomor Antrian}

Pada proses untuk mencetak nomor antrian ini tergantung pada sensor infra merah yang sudah terpasang. Disini led infra merah memancarkan sinar infra merah dan diterima oleh photodioda. Mikrokontroler akan mengecek keadaan input yang diberikan oleh sensor infra merah berulang-ulang. Selama tidak ada yang menghalangi sensor infra merah maka input yang diberikan pada mikrokontroler berlogika 1, bila ada yang menghalangi maka input yang diberikan pada mikrokontroler berlogika 0 dan output akan diberikan. PC akan membaca input dari mikrokontroler. Pertama kali program dijalankan nomor antrian dimulai dari angka 0 , Jika input pada $\mathrm{PC}$ adalah logika 0 maka nomor antrian akan bertambah 1 .

Kemudian printer akan mencetak nomor antrian seperti Gambar. Jika nomor antrian telah mencapai angka 1000 maka nomor antrian akan diulang menjadi angka 0 kembali. Bila nomor sudah tercetak, pengunjung diminta untuk mengambil cetakan nomor tersebut sebagai nomor panggilan.

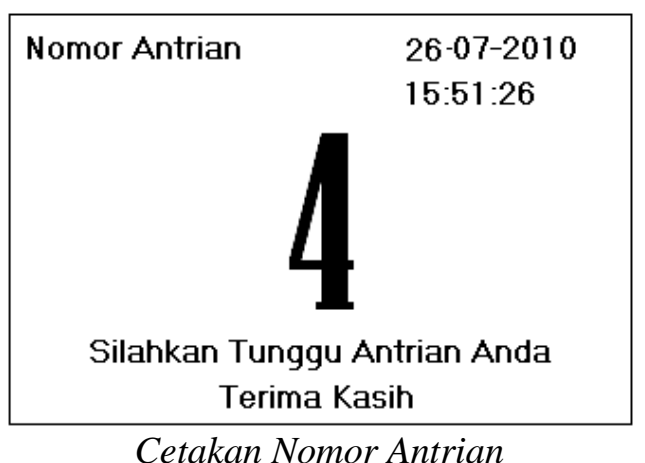

\section{Pemanggilan Nomor Antrian}

Pada proses pemanggilan nomor antrian, nomor antrian yang akan dilayani akan ditampilkan pada monitor dan diperdengarkan melalui speaker. Bila salah satu switch dari ketiga switch yang ada ditekan oleh loket/teller maka nomor antrian yang akan dilayani akan tampil pada monitor dan diperdengarkan melalui speaker yang terhubung pada PC. Nomor antrian ini akan dilayani oleh loket/teller yang menekan switch. 


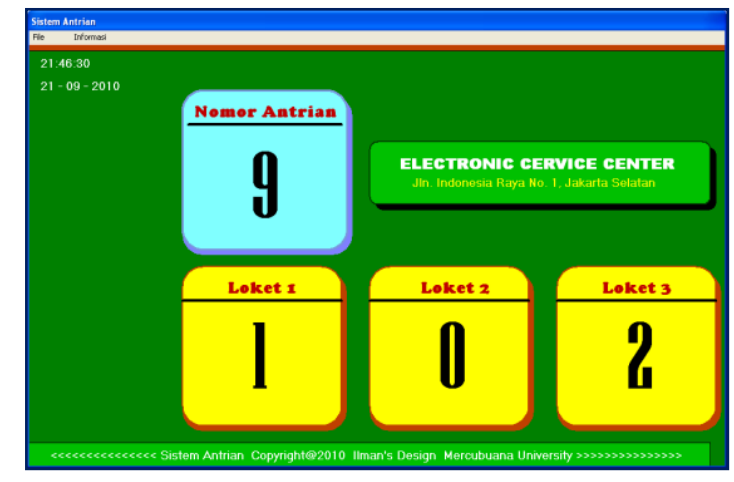

Panggilan Nomor Antrian Pada Monitor

\section{KESIMPULAN DAN SARAN}

\section{Kesimpulan}

Berdasarkan teori dan pembahasan yang telah dijelaskan pada bab yangsebelumnya, maka dapat disimpulkan bahwa :

1. Bahasa pemrograman Visual basic digunakan pada pembuatan sistem antrian ini karena bahasa pemrograman ini lebih mudah dipahami dan dipelajari, pengaplikasiannya pun cukup luas.

2. Printer yang digunakan pada sistem antrian ini akan mencetak nomor antrian jika sensor memberikan logika 0 pada mikrokontroler yang selanjutnya diberikan pada PC (personal computer)

3. Nomor antrian yang akan dilayani ditampilkan pada monitor jikasalah satu switch ditekan, atau mikrokontroler mendapatkan logika 0.

4. Speaker akan mengeluarkan suara sesuai dengan switch yang ditekan dan nomor yang akan dilayani.

5. Jika aplikasi ini belum dilengkapi dengan fasilitas Reset untuk mengatur nomor antrian dan nomor panggilan.

6. Aplikasi ini tidak dapat dijalankan jika rangkaian sensor belum terkoneksi dengan PC dan akan menampilkan pesan error.

\section{Saran}

Penulis ingin menambahkan beberapa hal penting yang perlu diperhatikandalam pembuatan program, yakni :

1. Pada pembuatan program ini masih memerlukan pengembangan dan penyesuaian yang lebih lanjut sesuai dengan kondisi hardware.

2. Untuk pengembangan pemrograman lebih lanjut disarankan agar dapat memperdalam teknologi pemrograman khususnya mengenai interfacing hardware dan software.

3. Selain bahasa pemrograman Visual Basic dapat juga digunakan bahasa pemrograman lainnya.

4. Selain bahasa Assembly Pinnacle 52 dan ISP-Flash dapat juga digunakan Assembler Compiler lainnya. 


\section{DAFTAR PUSTAKA}

Alam, M. Agus J.,Microsoft Visual Basic Versi 6.0. Jakarta: PT. Elek Media Komputindo, 2002.

Albert Paul Malvino, Ph. D, Alih Bahasa: M.O. Tjia, Ph.D. Institut Teknologi Bandung, Elektronika Komputer Digital. Jakarta: Erlangga, 1993.

Budiharto, Widodo, Perancangan Sistem dan Aplikasi Mikrokontroller. Jakarta:Erlangga, 2005.

Eko Putra, Agfianto,Belajar Mikrokontroller AT89S52 Teori dan Aplikasi. Yogyakarta: Penerbit ANDI,2004.

Kurniadi, Adi,Pemrograman Microsoft Visual Basic 6.0,Jakarta: PT. Elex Media Komputindo, 2000.

RA. Penfold,Dasar-Dasar Elektronika Untuk Pemula, Bandung : Pionir Jaya, 1999.

Rodnay Zaks, Austin Lesea, Penerjemah: Ir.SofyanH. Nasution, M.Sc.,
Teknik Perantaraan Mikroprosesor. Jakarta: Erlangga, 1993.

\section{Dari Website :}

- MIKROKONTROLER T89S52, SINAR INFRA MERAH, SISTEM SENSOR INFRA MERAH, http://www.ittelkom.ac.id

- TEKNOLOGI MIKROKONTROLER TERKINI, http://www.tokoelektronika.comtutorialuc $2 . \mathrm{html}$

- PANDUAN PRAKTIKUM DASAR MIKROKONTROLER, http://www.innovativeelectronics.com

- RANGKAIAN SENSOR INFRAMERAH, http://www.infogigi.com

- SKEMA RANGKAIAN SENSOR INFRAMERAH, http://electronicandlife.blogspot.com 